\title{
DA PAUTA AO PLAY: relato desenvolvimento de newsgames \\ de pesquisa aplicada para
}

FROM RULING TO PLAY: report of applied research for the development of newsgames

DE LA PAUTA AL JUEGO: informe de investigación aplicada para el desarrollo de newsgames

\section{Carlos Marciano}

Doutor e mestre pelo Programa de Pós-Graduação em Jornalismo da UFSC (Posjor/UFSC). Pesquisador do Observatório da Ética Jornalística (objETHOS/UFSC), do Núcleo de Estudos e Produção Hipermídia Aplicados ao Jornalismo (Nephi-Jor) e do grupo Educação, Comunicação e Mídias no Programa de Pós-Graduação em Educação (Edumídia - PPGE/UFSC). Atua como produtor de conteúdo na Secretaria da Comunicação Social e da Cultura do Paraná. É professor no Curso Superior de Tecnologia em Jogos Digitais, do Centro Universitário de Brusque - UNIFEBE. carlosnmarciano@gmail.com.

0000-0002-6567-3340

\begin{abstract}
RESUMO:
Os newsgames ganham cada vez mais espaço como uma nova linguagem do jornalismo, levando a informação através da ludicidade dos jogos. Nesse sentido, estimular o desenvolvimento dessa ferramenta torna-se crucial. Este artigo deriva da tese de doutorado que utilizou-se da pesquisa aplicada para estabelecer uma metodologia para desenvolvimento de newsgames. Assim, é apresentada aqui uma síntese do trabalho, ressaltando o conceito chave do Game Design Document para Newsgames (GDDN), além do método utilizado na oficina para o planejamento e desenvolvimento dos jogos jornalísticos, realizada na Universidade Federal de Santa Catarina (UFSC), que uniu profissionais do mercado de trabalho, estudantes de graduação e pós-graduação.
\end{abstract}

PALAVRAS-CHAVES: newsgames, pesquisa aplicada, jornalismo

\section{Introdução}

Antes de ser divulgada, uma matéria para rádio, TV, impresso ou internet é planejada, apurada e só então produzida. Utilizar jogos no jornalismo também segue essa lógica, sendo necessário planejamento antes de sair colocando a mão nos códigos.

No sentido de clarear os horizontes sobre esse processo de construção dos jogos jornalísticos, este artigo apresentará o método utilizado na oficina "GDD para newsgames (GDDN)", que integrou a disciplina "Tópicos Especiais em Jornalismo XVII Questões Empíricas e Aplicadas da Pesquisa em Jornalismo", na qual três newsgames foram desenvolvidos.

A disciplina foi ministrada em 2018, na Universidade Federal de Santa Catarina (UFSC), tendo como público-alvo estudantes de graduação e pós-graduação em jornalismo, além de profissionais do mercado de trabalho.

Trata-se aqui de uma pesquisa aplicada que tem como base a metodologia ativa de aprendizagem proposta por Moran (2013). Na ocasião, fez-se uso de três métodos propostos pelo autor: "aprendizagem baseada em projetos", na qual os alunos se 
envolveram com tarefas e desafios para desenvolver um projeto; "aprendizagem colaborativa, entre os pares", a partir da definição dos grupos de interesse presenciais que compartilharam os saberes para sanar as dúvidas; e "aprendizagem personalizada", no sentido de que as atividades foram adaptadas ao ritmo e à necessidade de cada grupo.

A fim de sistematizar essa proposta e deixar mais claro como a oficina foi planejada, o presente artigo está organizado em quatro seções: Conceitos e definições de newsgames, o Game Design Document para Newsgames (GDDN); Descrição metodológica da oficina; Newsgames desenvolvidos.

As duas primeiras remetem ao conteúdo teórico central apresentado aos alunos, que conceitua, define e estrutura o planejamento dos newsgames. As duas seguintes, expõem a caracterização e organização da oficina, bem como os jogos desenvolvidos nela.

Deste modo, ao divulgar os caminhos trilhados na oficina "GDD para newsgames (GDDN)", espera-se que este trabalho seja um guia inicial no desenvolvimento de newsgames, no sentido de que outras pessoas, jornalistas ou não, possam replicar os passos aqui expostos e assim planejar e produzir ou orientar a produção de novos jogos jornalísticos.

\section{Conceitos e definições dos newsgames}

Na tentativa de propor reflexões sobre política por meio de seus jogos, o jornalista e designer uruguaio Gonzalo Frasca (2003) cunhou em meados de 2001 o termo newsgaming. Surgia então um estilo de jogo com a proposta de transmitir a opinião do desenvolvedor, com característica das charges e cartuns políticos dos jornais.

Adaptado para newsgame, o termo remete aos jogos cujo conteúdo se origina de notícias ou acontecimentos em curso de modo que, por meio dos objetivos e mecânicas, o jogador é transportado para o cenário retratado e pode, assim, refletir sobre aquele tema.

Igualmente como Frasca (2003), Sicart (2008) também considera que o debate público está presente na dinâmica dos newsgames. Por sua vez, Treanor e Mateas (2009) reforçam a aproximação dos jogos jornalísticos com as charges políticas, mas salientam a necessidade de os elementos gráficos e interativos desses jogos estimularem no jogador o mesmo posicionamento do veículo sobre o tema abordado. 


\section{Obevisto}

Treanor e Mateas (2009) acreditam ainda que a relevância dos newsgames está no foco persuasivo de seu conteúdo, permitindo desse modo que eles continuem chamando atenção, mesmo que o assunto não seja mais destaque na imprensa.

Os autores ilustram esse posicionamento citando September $12^{\text {th }}$, jogo desenvolvido por Gonzalo Frasca e lançado em 2003, com o intuito de causar reflexão sobre a estratégia americana de efetuar um "bombardeio cirúrgico" como retaliação ao atentado terrorista de 11 de setembro de 2001.

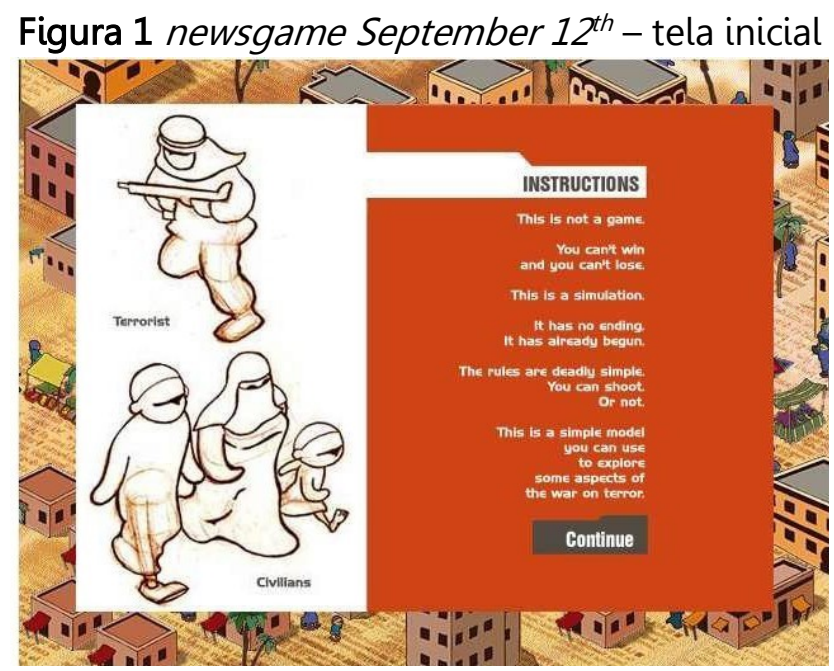

Fonte: http://www.newsgaming.com/games/index12.htm.

Para os autores, um newsgame pode enquadrar em mais de um gênero, desde que suas características contemplem as especificidades das diferentes modalidades.

Ao realizar uma busca por newsgames é possível encontrar projetos desenvolvidos tanto por veículos jornalísticos quanto por produtores independentes. Nesse último caso, os desenvolvedores nem sempre possuem formação na área do jornalismo, de modo que produzem o jogo inspirados em uma matéria jornalística, mas cujo foco é o entretenimento.

Marciano (2020) defende que os newsgames têm o propósito de informar ou propor uma reflexão sobre o conteúdo retratado, portanto, tais jogos inspirados em um conteúdo jornalístico, mas focados apenas no entretenimento não atendem esse requisito, sendo considerado pelo autor como um Jogo Embasado em Notícia (JEN).

Para estabelecer essa diferenciação, Marciano (2020) analisa se os conteúdos informativos estão presentes ou não dentro dos elementos gráficos do jogo, definindo assim três parâmetros: Presença Audiovisual Direta do Conteúdo Informativo (PADCI); Equipe de Produção e Apuração (EPA); Presença Audiovisual Direta das Fontes (PADF). 
A Presença Audiovisual Direta do Conteúdo Informativo (PADCI) visa identificar se o jogo foca no entretenimento ou apresenta elementos que agreguem algo ao conteúdo ou temática original.

No caso de newsgames, a PADCl atua através da informação jornalística que é "apresentada de alguma forma dentro do jogo (texto, vídeos, fotos, ilustrações), propondo, assim, uma reflexão, um conteúdo extra ou um contraponto sobre o tema/informação retratado" (MARCIANO, 2020, p.66).

Como o foco do Jogo Embasado em Notícia (JEN) é o entretenimento, a PADCI não se manifesta, de modo que os elementos gráficos são apenas referências ao conteúdo jornalístico de inspiração, ou seja, inexistem neles informações que agreguem ou proponham reflexão sobre a temática abordada.

A Equipe de Produção e Apuração (EPA) busca identificar se dentre os desenvolvedores do jogo existe alguém responsável pela apuração jornalística do conteúdo.

$\mathrm{Na}$ equipe de desenvolvimento de um newsgame existe ao menos uma pessoa, normalmente um jornalista, responsável por apurar o conteúdo, checar a veracidade dos fatos e definir o que será retratado e inserido no jogo. O nome dos desenvolvedores e suas respectivas funções costuma ficar visível em alguma parte do newsgame destinada aos créditos.

Já na produção dos Jogos Embasados em Notícias (JEN) não existe a preocupação em apurar/verificar o conteúdo, sendo necessário apenas uma temática jornalística para referência. Muitas vezes esses jogos não apresentam um campo com o nome dos desenvolvedores.

Por fim, a Presença Audiovisual Direta das Fontes (PADF) tem o propósito de identificar se o jogo apresenta as fontes originais que serviram de referência para a temática abordada.

Em um newsgame, apresentar as fontes informativas reforça o aspecto e caráter jornalístico, de modo que as fontes são normalmente apresentadas de forma direta, em algum menu do jogo, ou através de links nos objetos de gameplay.

Já nos Jogos Embasados em Notícia (JEN) a ausência da origem das informações sinaliza a prioridade do entretenimento e, eventualmente, a fonte que embasou o tema é apresentada. Nesse sentido, ainda que os elementos gráficos e sonoros remetam ao material jornalístico, o jogador só entenderá essa referência caso tenha um contato anterior com o conteúdo que serviu de inspiração à produção jogo, ao contrário dos newsgames que disponibilizam o fácil acesso a fonte original. 
Para garantir que um jogo seja de fato um newsgame, Marciano (2020) recomenda que o mesmo apresente os três parâmetros, mas reforça que é a Presença Audiovisual Direta do Conteúdo Informativo (PADCI) o requisito diferenciador:

Não basta apenas dizer no layout de créditos que um jornalista participou do desenvolvimento, tampouco colocar isoladamente o link para a matéria de origem. O que distingue o newsgame do Jogo Embasado em Notícia (JEN) é o fato de o primeiro apresentar informações que agregam ou propõem alguma reflexão sobre o conteúdo de referência, estejam elas presentes no gameplay ou nos layouts internos (MARCIANO, 2020, p.71).

Além de compreender essas definições, para se desenvolver um newsgame é necessário que haja um planejamento e estruturação das ideias antes de sair colocando a mão na massa.

É aí que entra o Game Design Document para Newsgames (GDDN) proposto por Marciano (2020), uma espécie de roteiro para a construção dos jogos jornalísticos.

\section{O Game Design Document para Newsgames (GDDN)}

Assim como a lauda no telejornalismo, o Game Design Document para Newsgame (GDDN) auxilia no trabalho da equipe, estruturando o que estará presente no jogo e deixando claro em que pontos dele o conteúdo jornalístico aparecerá.

Associando as definições de lide jornalístico estabelecidas por Lage (2001) e o GDD de dez páginas, colocado por Rogers (2014), em sua proposição, Marciano (2020) estrutura o Game Design Documento para Newsgames (GDD) em 13 tópicos, descritos brevemente a seguir:

1- História (O quê?): respondendo a primeira pergunta do lide jornalístico (O quê?), esse tópico detalha a história do jogo com começo meio e fim, apresentando o tema ou matéria que serve como base ao newsgame.

2- Objetivos (Por quê?): assim como a sexta pergunta do lide (Por quê?) descreve a causa do fato noticiado, neste tópico é descrito qual o propósito do jogo (educativo, comercial, etc), a que público ele se destina e o que o jogador precisa fazer para concluí-lo.

3- Equipe e deadline: neste item é definido quantos integrantes participarão do projeto e suas funções, bem como o tempo disponível para desenvolvimento. Para dividir melhor as tarefas, o autor recomenda que a equipe mínima seja 
composta de um jornalista (responsável por apurar o conteúdo jornalístico e verificar como ele está sendo inserido no newsgame), um programador (cuja função é dar vida ao jogo, seja codificando o game digital ou confeccionando o tabuleiro, cartas e peças do jogo analógico) e um artista (que desenvolverá os elementos gráficos do jogo, como cenários, personagens e sons).

4- Gameplay e plataforma (Como?): este é um dos tópicos mais importante do GDDN, pois detalhará a mecânica do jogo, tais como movimentação e ações dos personagens e inimigos, condições de vitória e derrota, estilo de jogo (plataforma, cartas, tabuleiro, etc), recompensas e desafios, além de onde ele será disponibilizado ( $\mathrm{PC}$, navegadores, consoles, android, IOS, etc). A pergunta cinco do lide (Como?) apresenta a maneira como o fato ocorreu. Do mesmo modo este tópico descreve todos os aspectos técnicos do jogo, ou seja, como ele deverá ser desenvolvido e jogado, e onde as informações jornalísticas aparecerão no newsgame.

5- Personagens (Quem?): no lide jornalístico, a segunda pergunta (Quem?) sinaliza os envolvidos na matéria. Da mesma forma, este tópico do GDDN deve descrever quem são os personagens do jogo, incluindo suas características físicas, personalidade, ações e qual seu papel na narrativa do newsgame.

6- Inimigos: caso o newsgame tenha inimigos como monstros ou itens que causam danos, os mesmos devem ser detalhados nesse tópico, sinalizando, dentre outras coisas, como eles são, em que momentos do jogo aparecem e como eles afetam o progresso do jogador (retiram vidas, subtraem pontos, etc). É importante frisar que neste tópico deve ser descrito tudo aquilo que coloca dificuldade para o avanço do jogador, ou seja, um jogo que não apresenta inimigos no formato de avatares, mas possui suas fases cronometradas, tem o tempo como empecilho, sendo necessário descrever aqui como o correr do relógio pode afetar o avanço no newsgame.

7- Universo do jogo (Quando?, Onde?): neste tópico deve ser detalhado o ambiente do jogo, ou seja, como serão os cenários, quantas fases o jogo terá, qual a ligação delas, etc. No lide jornalístico, a pergunta 3 (Quando?) situa sobre o momento em que o fato ocorreu, enquanto a pergunta 4 (Onde?) apresenta o local do fato. A mesma lógica é descrita aqui para o newsgame, de modo que o universo do jogo irá situar o jogador no tempo e local em que a história se passa. 
8- Controles: neste tópico é detalhado as características de input e output do newsgame, ou seja, quais os comandos que o jogador deverá executar para interagir (apertar botões, clicar, rolar a tela) e ao que eles corresponderão no jogo (movimentar o personagem, passar de cenário, etc). É importante ressaltar que se um newsgame for desenvolvido para mais de uma plataforma, é imprescindível que neste tópico seja descrita a forma de interação em cada uma delas (por exemplo, uso de joystick para jogar no PC e comandos de toque na tela para aparelhos móbile).

9- Câmera: este tópico refere-se à visualização que o jogador terá dos objetos do newsgame, como visão do jogo em primeira ou terceira pessoa. Caso existam diferentes visualizações no newsgame é necessário definir aqui onde ocorrerá essas alterações, por exemplo, na transição entre cenários.

10-Interface: neste tópico deve ser descrito como os elementos visuais estarão dispostos nas telas de jogo, tais como ordem dos botões, inventário, posição de inimigos e itens, além dos elementos de indicação do jogo, conhecidos como HUD ${ }^{1}$ (Heads-Up Display).

11-Cutscenes: este tópico trata dos vídeos, textos ou animações inseridas no meio do jogo para explicar ou ilustrar algo da história. Caso os desenvolvedores optem por inseri-las no newsgame, deve-se detalhar aqui em quais momentos as cutscenes irão aparecer, descrever o roteiro delas, bem como definir as ferramentas utilizadas para sua produção e captação.

12-Cronograma: com o deadline definido, é importante que os desenvolvedores façam um planejamento das atividades, descrevendo neste tópico como as tarefas serão divididas entre a equipe e qual o prazo para execução. A boa gestão do cronograma facilita o trabalho e garante a qualidade no newsgame, assim, recomenda-se uma reunião semanal de acompanhamento, a fim de verificar se os trabalhos estão dentro do prazo e solucionar qualquer imprevisto.

13-Orçamento: ter o controle dos gastos em qualquer projeto é fundamental e no desenvolvimento de jogos jornalísticos não seria diferente. Caso a equipe receba financiamento para a produção do newsgame, é neste tópico que os

1 Heads-Up Display (HUD) são marcações na tela, conhecidas nos jogos como atributos. Elas servem para situar o jogador dentro do game, de modo que ele possa acompanhar o seu progresso (quantidade de vida, poderes, itens coletados, cronômetro indicando quanto tempo falta para o jogo acabar, etc.). 
custos devem ser detalhados, inserindo em uma planilha todos os gastos, tais como mão de obra, equipamentos, softwares, manutenção do espaço, publicação e marketing.

Ao analisar o Game Design Document para Newsgames (GDDN) proposto por Marciano (2020), percebe-se que os 13 itens podem ser organizados em três grupos: Tópicos Obrigatórios, Tópicos Opcionais e Tópicos Administrativos.

Os Tópicos Obrigatórios referem-se aqueles itens que devem constar no planejamento de qualquer newsgame, e estão relacionados diretamente ao detalhamento técnico do jogo.

Assim, esse grupo é composto por oito tópicos: História (O quê?), Objetivos (Por quê?), Universo do Jogo (Onde? Quando?), Equipe e deadline, Controles, Gameplay e Plataforma (Como?), Câmera e Interface.

Formado pelos itens Personagens (Quem?), Inimigos e Cutscenes, o grupo Tópicos Opcionais refere-se aos elementos que podem integrar ou não o newsgame, dependendo da mecânica de gameplay escolhida pela equipe de desenvolvimento.

Por exemplo, uma equipe que pretende desenvolver um newsgame no qual os conteúdos jornalísticos são apresentados utilizando a mecânica do jogo de cartas, não necessita preencher esses três itens do Game Design Document para Newsgames (GDDN), visto que o jogo não terá nenhum personagem controlado pelo jogador, cutscenes ou um tempo mínimo para ser jogado.

Por fim, o grupo Tópicos Administrativos engloba os itens Cronograma e Orçamento. Mesmo que um newsgame tenha um deadline grande e não tenha receita para seu desenvolvimento, é importante que a equipe pense nesses dois itens ao escrever o Game Design Document para Newsgame (GDDN).

Eles foram separados dos demais não porque são dispensáveis, mas sim por se referirem a aspectos administrativos do projeto, ao contrário dos outros que estão diretamente ligados a parte técnica dos jogos.

Nesse sentido, fazer o exercício de definir no GDDN um cronograma e orçamento ajuda a organizar melhor o trabalho, além de que esses dois tópicos serão requisitados caso as equipes submetam o projeto a algum edital de financiamento.

É importante ressaltar que "um newsgame não precisa, obrigatoriamente, abranger todos os tópicos do GDDN aqui apresentados; no entanto, é necessário que sua estrutura informativa e de gameplay estejam bem definidas" (MARCIANO, 2020, p.86). 
Ou seja, para ser considerado newsgame é imprescindível que o conteúdo jornalístico esteja presente de forma clara no jogo (fases, personagens, menus, etc), no intuito de propor no jogador uma reflexão, contraponto ou complemento ao tema abordado.

A conceituação do Game Design Document para Newsgame (GDDN) serviu como base da Pesquisa Aplicada desenvolvida no formato de oficina, no curso de jornalismo da Universidade Federal de Santa Catarina.

A descrição da atividade bem como alguns dos resultados serão apresentados a seguir.

\section{Descrição metodológica da oficina}

Com o propósito de aplicar o Game Design Document para Newsgames (GDDN) apresentado anteriormente e fazer com que os alunos planejassem e produzissem jogos jornalísticos, a oficina de desenvolvimento teve como público-alvo estudantes de graduação e pós-graduação em jornalismo, além de profissionais do mercado de trabalho.

Ela integrou a disciplina "Tópicos Especiais em Jornalismo XVII - Questões Empíricas e Aplicadas da Pesquisa em Jornalismo", ministrada em 2018, na Universidade Federal de Santa Catarina (UFSC).

A oficina foi dividida em seis encontros, com duração de 4 horas cada, sendo ministrada para 20 estudantes e desenvolvida no laboratório de informática equipado com desktops, retroprojetor, lousa, conexão estável à internet via cabo de rede e mesas para trabalho.

Além do desktop ligado ao retroprojetor, que era utilizado na apresentação dos alunos e para explicação dos professores, foi disponibilizado aos estudantes os seguintes materiais:

1- formulário para consulta e identificação dos conceitos de newsgames,

2- formulário para o preenchimento do GDDN, contendo explicação de cada um dos 13 tópicos;

3- folhas pautadas, folhas sem pauta, lápis, borracha, régua e canetas;

4- 8 computadores no laboratório, todos equipados com o software Construct 2, disponíveis para que as equipes pudessem pesquisar e desenvolver o newsgame. 
Para a oficina foram estabelecidos dois objetivos:

1- apresentar o Game Design Document para Newsgames (GDDN) a fim de verificar se os tópicos expostos estavam claros a ponto de os participantes conseguirem planejar um jogo seguindo-os;

2- auxiliar as equipes quanto à programação no software Construct 2 para que conseguissem desenvolver ao menos uma das fases planejadas no GDDN.

O método de trabalho foi estruturado em cinco partes:

a) apresentação dos conceitos gerais sobre estudo dos jogos;

b) apresentação conceitual dos Serious Games e newsgames, das categorias propostas por Bogost, Ferrari e Schwaizer (2010) e das etapas de desenvolvimento;

c) apresentação dos 13 tópicos do Game Design Document para Newsgames (GDDN) e da diferenciação entre newsgames e Jogos Embasados em Notícias (JEN);

d) criação de grupos a fim de que pudessem analisar os tópicos do GDDN, planejar um newsgame a partir dele e utilizar o formulário como consulta e registro do que foi definido em cada tópico durante o planejamento;

e) auxiliar as equipes no desenvolvimento dos jogos com o software Construct 2.

No primeiro encontro da oficina os alunos foram apresentados aos conceitos dos estudos de jogos, definições se Serious Games, além do conceito, categorias e processos de desenvolvimento dos newsgames. 
Figura 2: capa da apresentação da aula 1

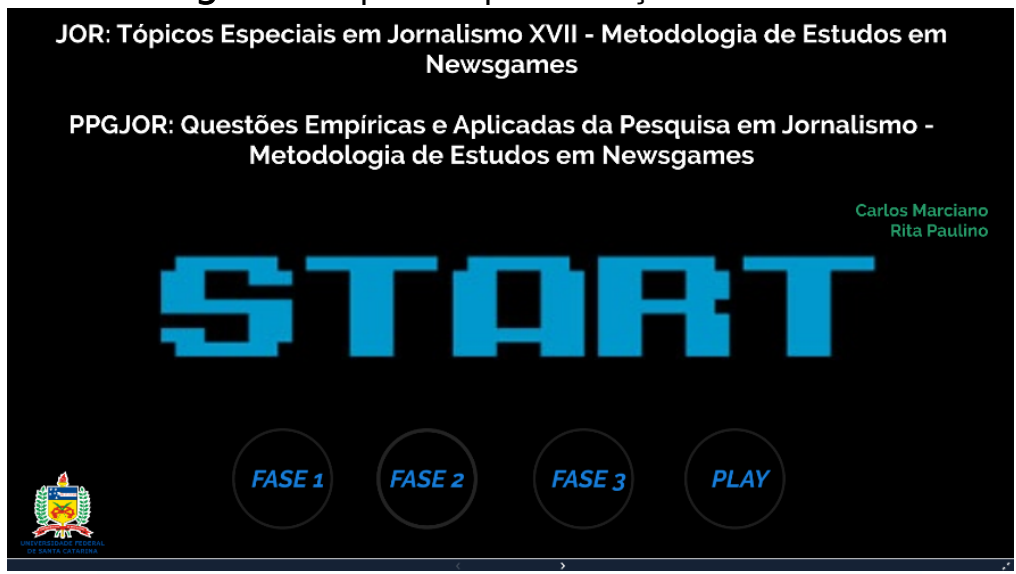

Fonte: https://prezi.com/view/1rYthrYiBlw3uHH9bEf7/

No intuito de introduzir os alunos ao tema da aula seguinte, ao final da primeira aula foi passado para eles um exercício de análise de newsgames.

Figura 3: exercício proposto no primeiro encontro

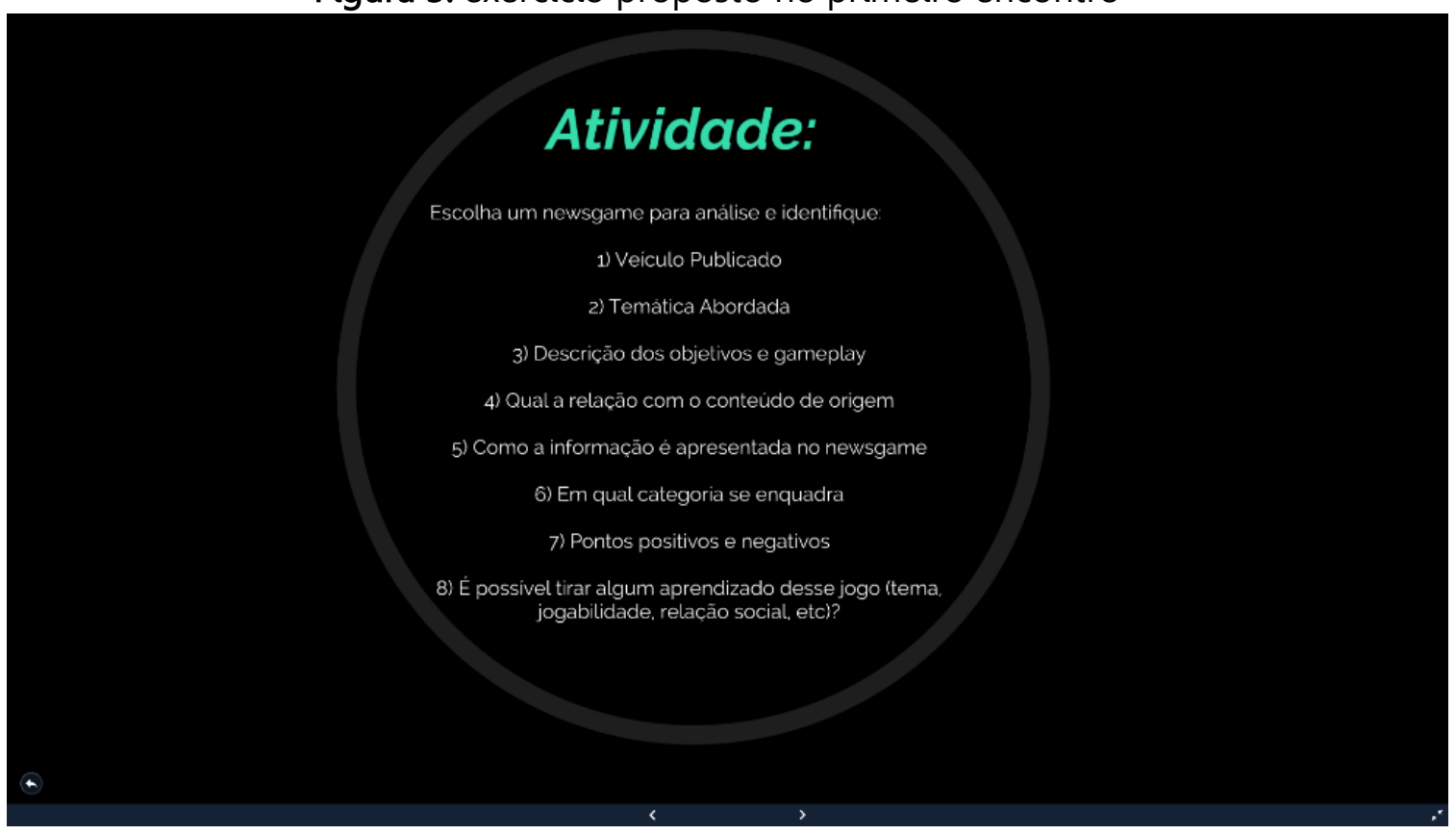

Fonte: https://prezi.com/view/1rYthrYiBlw3uHH9bEf7/

O Game Design Document para Newsgames (GDDN) foi apresentado aos alunos no segundo encontro, bem como a diferenciação entre Newsgames e Jogos Embasados em Notícias (JEN). 
Figura 4: capa da apresentação da aula 2

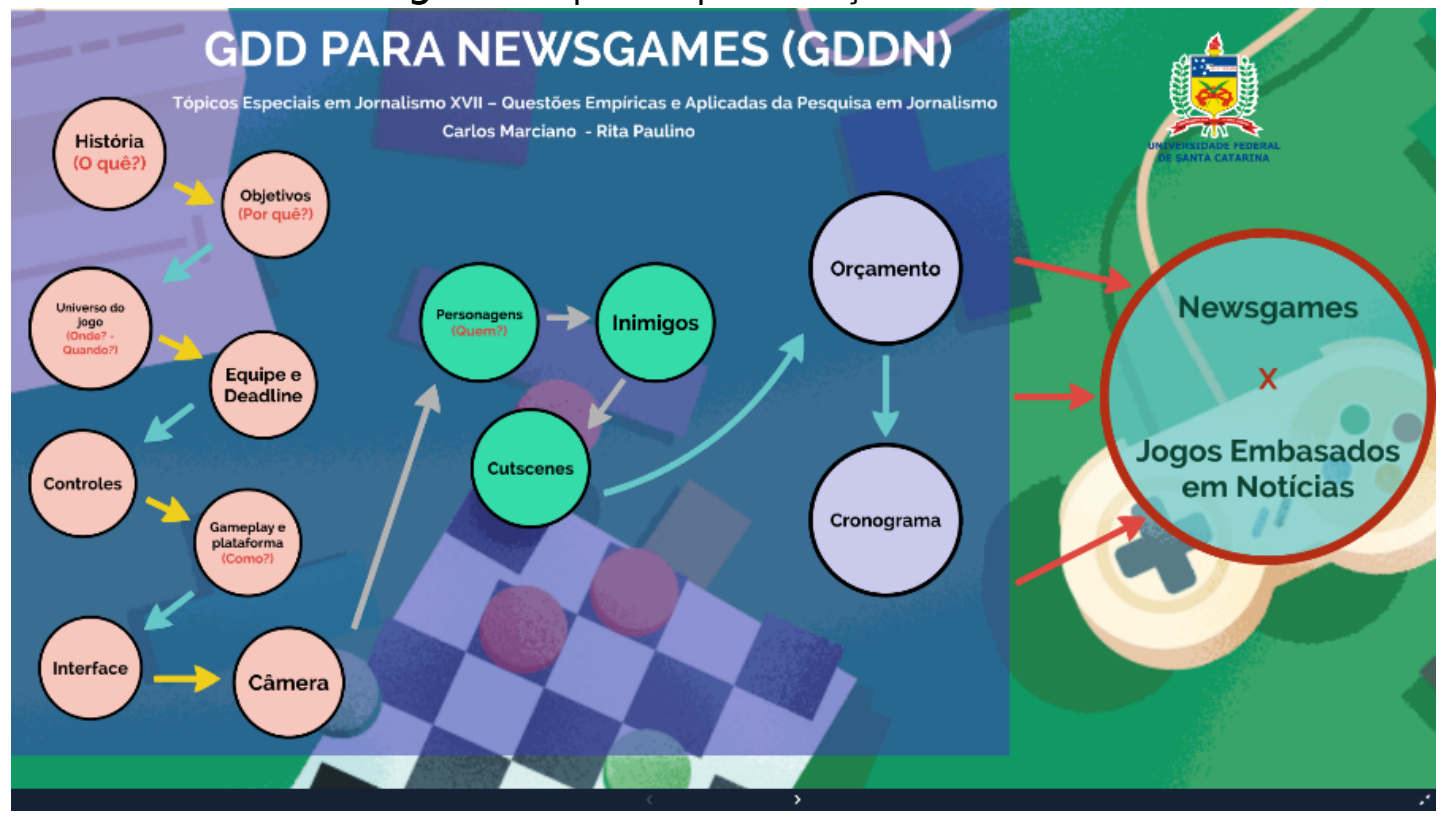

Fonte: https://prezi.com/view/1rYthrYiBlw3uHH9bEf7/

Após serem apresentados aos conceitos, os quatro encontros seguintes foram disponibilizados para que os alunos pudessem desenvolver os newsgames.

Assim, os estudantes foram divididos em grupos, de modo que cada equipe precisaria:

1- escolher um tema e desenvolver um material jornalístico inédito que serviria de base para o projeto;

2- planejar o jogo, estruturando-o com o preenchimento dos tópicos do GDDN;

3- produzir um newsgame digital utilizando o software Construct 2.

A fim de padronizar e garantir que os produtos desenvolvidos fossem considerados newsgames, os jogos deveriam atender a seis requisitos:

a) Tela de menu: com o nome do jogo e no mínimo um botão que direcionasse para a tela de gameplay.

b) Informações com os créditos do jogo: ou seja, apresentar uma tela com o nome dos desenvolvedores e suas respectivas funções.

c) Informações sobre o jogo: apresentando a temática abordada e o contexto em que o newsgame foi desenvolvido. 
d) Tela de gameplay: com pelo menos uma fase jogável completa e ao menos um elemento que remetesse ao tema abordado na matéria produzida pela equipe.

e) Telas de vitória e derrota: acessadas, respectivamente, quando o jogador ganhasse e perdesse o jogo.

f) Link para apresentar a reportagem em uma nova aba do navegador: podendo este ser através de um botão ou elemento interativo no gameplay.

Cientes desses requisitos, as equipes se reuniram para estruturação do GDDN e a codificação dos newsgames, sendo apresentados a seguir três projetos desenvolvidos: SOS Hercílio, Fact-checking O Jogo - Fato ou Fake, e Mete a Colher.

\section{Newsgames desenvolvidos}

Após conhecerem os conceitos e estruturarem o newsgame no GDDN, cada equipe iniciou o desenvolvimento do jogo idealizado utilizando para codificação o software Construct 2.

Na prática, os ministrantes apresentaram o Construct 2 para os alunos, explicaram como ele funcionava e só depois cada equipe dedicou-se ao respectivo projeto, tendo o acompanhamento de perto dos professores para solucionar as dúvidas relativas aos aspectos conceituais e de codificação.

É importante frisar aqui que qualquer software de desenvolvimento de jogos poderia ser utilizado nessa etapa da metodologia, de modo que o Construct 2 foi escolhido pelos ministrantes da oficina por ser, na época, uma ferramenta gratuita, com interface amigável e de fácil manuseio, pois não requisita conhecimento prévio de alguma linguagem de programação.

Nesse sentido, a apresentação dos jogos a seguir visa ilustrar os resultados e tem como foco o conteúdo e forma de cada newsgame, permitindo assim apresentar a metodologia desenvolvida na oficina sem restringir sua aplicação a determinada ferramenta. 


\section{SOS Hercílio ${ }^{2}$}

Desenvolvido pelos estudantes Letícia Beilfuss, Luciana Leão, Luíz Cláudio, Ricardo Aoki e Thiago Malkowski, o newsgame teve como tema a ponte Hercílio Luz, cartão-postal da cidade de Florianópolis.

Tanto a matéria quanto o newsgame contam a história da construção da ponte, inaugurada em 1926, destacando o imbróglio por trás de sua restauração.

A tela de menu corresponde ao requisito "a", pois apresenta o nome do jogo centralizado e os botões "Jogar", "Ler a Notícia" e "Sobre".

Figura 5: newsgame SOS Hercílio - tela de menu

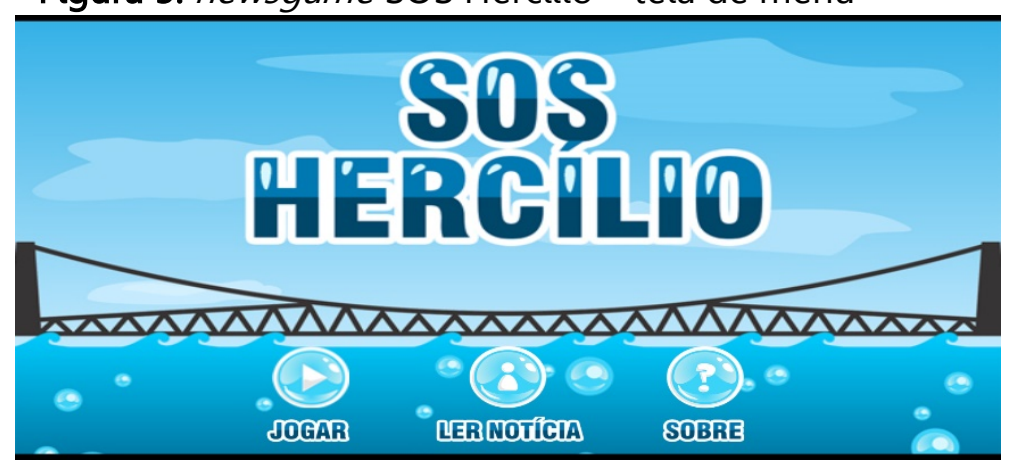

Fonte: https://aokittos.itch.io/sos-hercilio

Embora a matéria que serviu de base para o newsgame não tenha sido apresentada em um link externo, o requisito " $\mathrm{f}$ " também foi contemplado, pois a mesma é apresentada integralmente dentro do jogo, sendo acessada quando o jogador clica no botão "ler notícia".

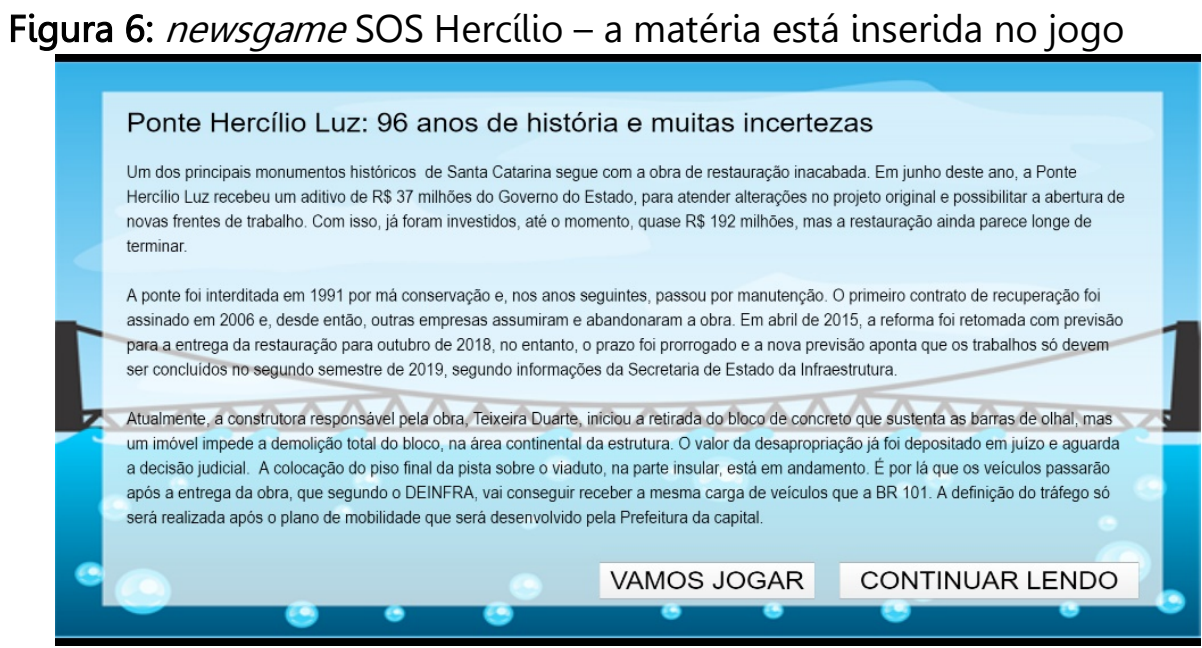

Fonte: https://aokittos.itch.io/sos-hercilio 
Na tela de gameplay, antes da fase iniciar é apresentada ao jogador uma tela de instrução, indicando quais são os controles e o objetivo do jogo: abrir o acesso até Florianópolis acendendo todas as lâmpadas da ponte.

Figura 7: newsgame SOS Hercílio - Tela de instruções

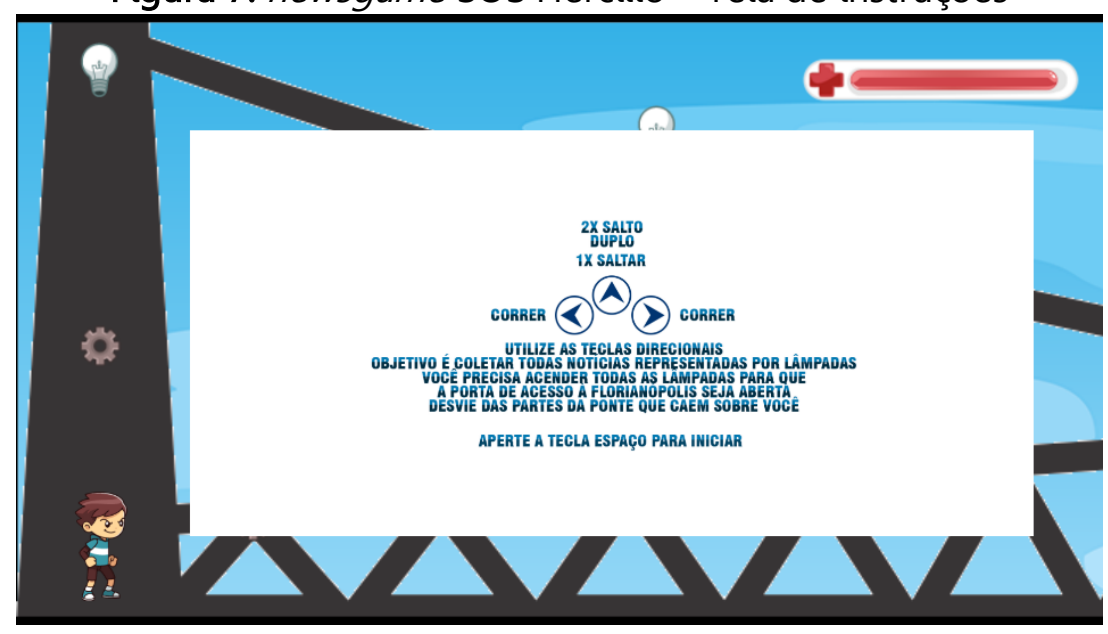

Fonte: https://aokittos.itch.io/sos-hercilio

Conforme observado na Figura 8, no controle de um personagem que representa um turista caminhando pela ponte, o jogador precisa evitar ser atingido pelas engrenagens (1) e a cada lâmpada acesa (2) o jogo pausa e uma informação complementar à matéria aparece na parte superior da tela (3), atendendo assim ao requisito " $d$ ". Vale ressaltar que, ao contrário do que aparece no canto inferior esquerdo (4), para continuar o jogo é necessário apertar a tecla de espaço, e não a tecla "b".

Figura 8: newsgame SOS Herćlio - Tela de gameplay: itens e informações

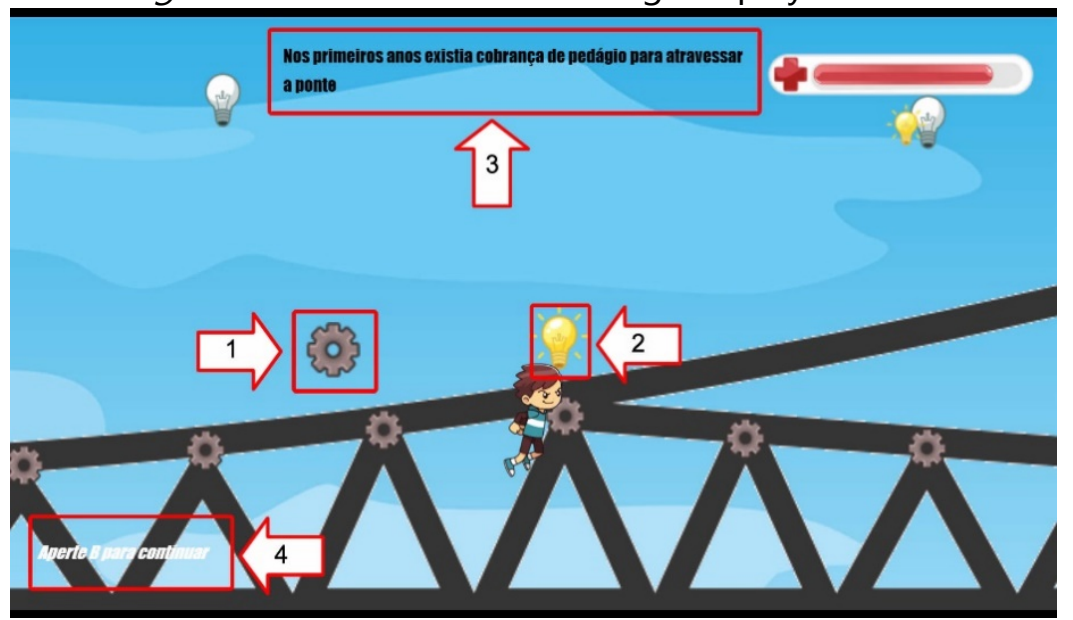

Fonte: https://aokittos.itch.io/sos-hercilio 


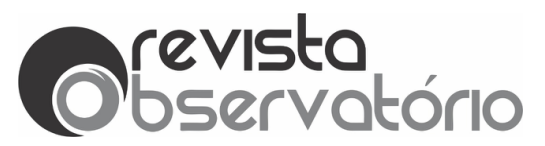

e-ISSN n² 2447-4266

Palmas, v. 7, n. 3, p. 1-26, jul.-set., 2021

Cada engrenagem que atinge o jogador tira um pouco da vida do personagem e se esta chegar a zero o jogo acaba e aparece a tela de derrota. Se ele conseguir acender as 14 lâmpadas a condição de vitória é atingida e o jogador é direcionado para a tela de vitória. Assim, cumpre-se também o requisito "e".

Figura 9: newsgame SOS Hercílio - Tela de derrota

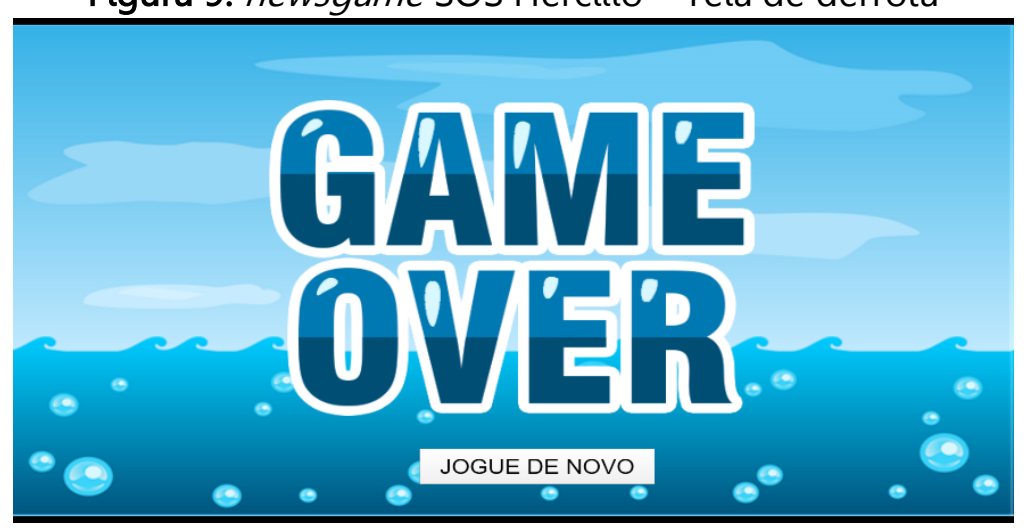

Fonte: https://aokittos.itch.io/sos-hercilio

Figura 10: newsgame SOS Hercílio - tela de vitória

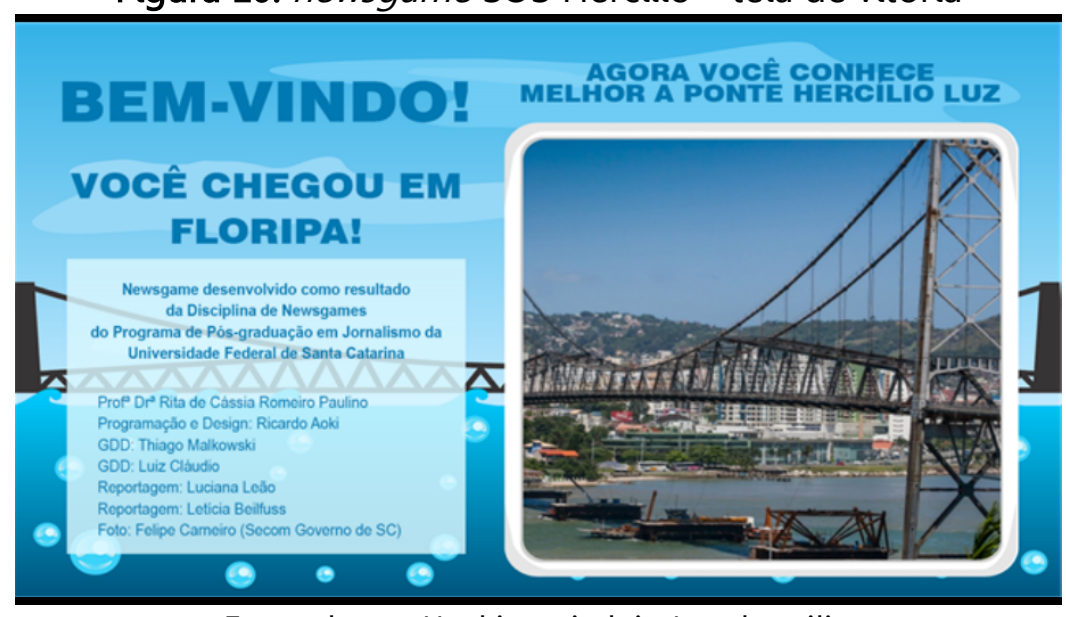

Fonte: https://aokittos.itch.io/sos-hercilio

É nessa tela também que estão presentes as informações dos desenvolvedores e o contexto em que o jogo foi produzido, atendendo assim aos requisitos "b" e "c".

\section{Fact-checking O Jogo - Fato ou Fake ${ }^{3}$}

Inspirados nas agências de checagem de informações, o newsgame desenvolvido pelos alunos Ana Carla Pimenta, César Rosati, Manoela Bonaldo, Thuane de Oliveira e 
Yanne Roberto, coloca o jogador na pele de um estagiário de jornalismo, com o objetivo de averiguar as informações repassadas pela chefe Maria.

A tela de menu do newsgame atende tanto o requisito "a" quanto o requisito " $f$ ", pois ela apresenta o nome do jogo, o botão que direciona para a tela de gameplay e também um botão simbolizado por uma lupa, que abre uma nova janela no navegador na qual é possível ler a reportagem multimídia que sustenta o jogo.

Figura 11: newsgame- Fact-checking - tela de menu

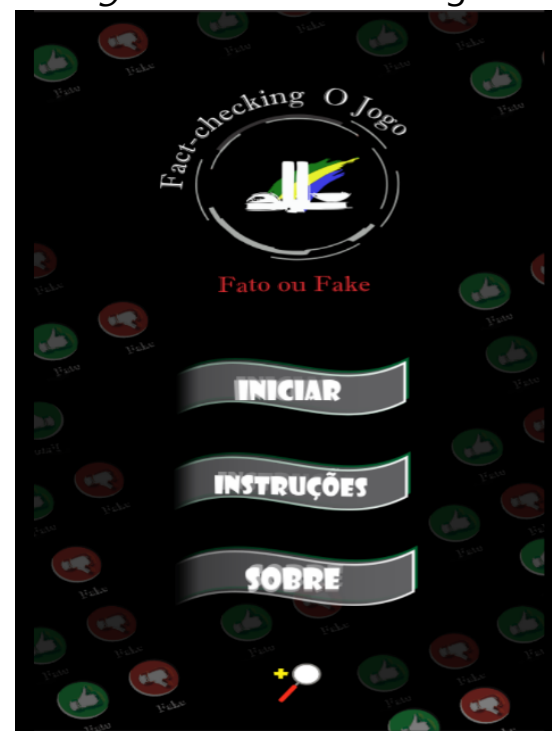

Fonte: https://marciano.itch.io/fact-checking

Ainda no menu é possível acessar a tela de instruções que situa o jogador na história. Por sua vez, ao clicar em "sobre" ele é direcionado para tela na qual é possível conferir o nome dos integrantes da equipe, suas funções e o contexto em que o newsgame foi desenvolvido, atendendo assim aos requisitos " $b$ " e " $c$ ". 
Figura 12: newsgame - Fact-checking - tela de sobre (esq) e instruções (dir)
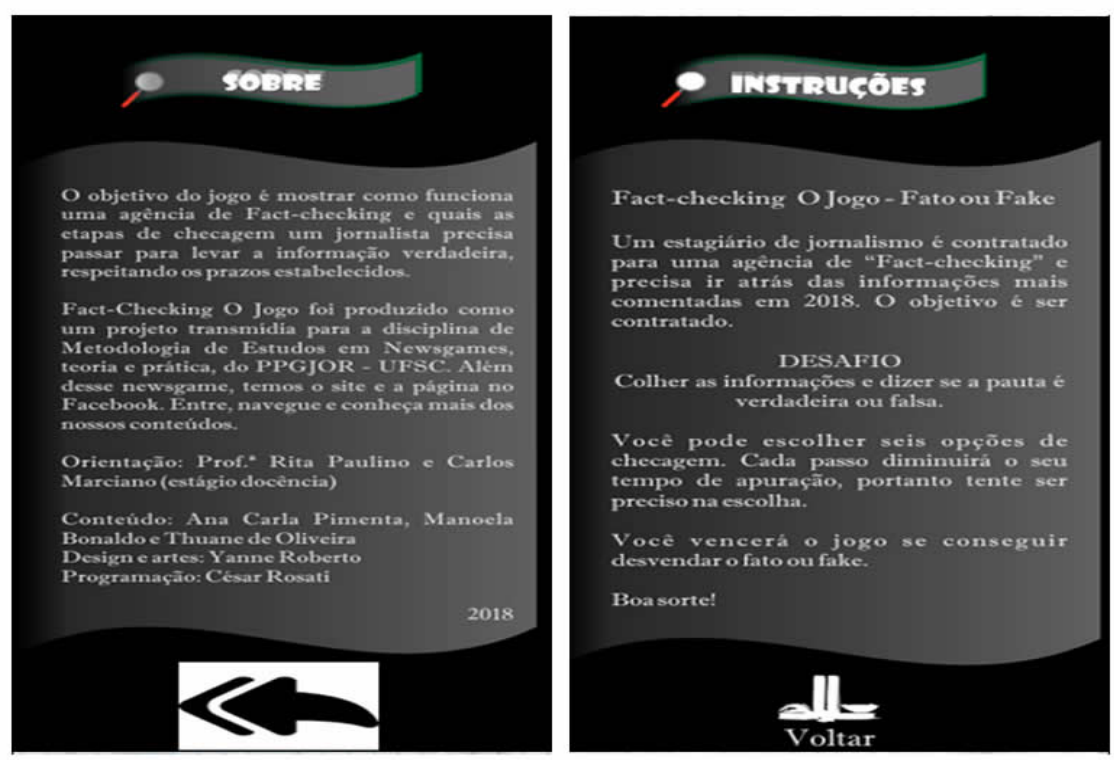

Fonte: https://marciano.itch.io/fact-checking

Desenvolvido na mecânica de quizz, o jogo consiste em receber a pauta da editora chefe Maria e fazer a verificação do conteúdo antes que o deadline (1) acabe. Para isso, o jogador poderá fazer a checagem em seis lugares (2) diferentes, sendo que cada um deles reduz o tempo de apuração. É possível ler a pauta novamente sempre que necessário (3), mas o botão para enviar a resposta (4) só ficará ativo quando faltar duas horas para acabar o prazo.

Figura 13: newsgame - Fact-checking - Tela de apuração (esq) e fala da fonte (dir)
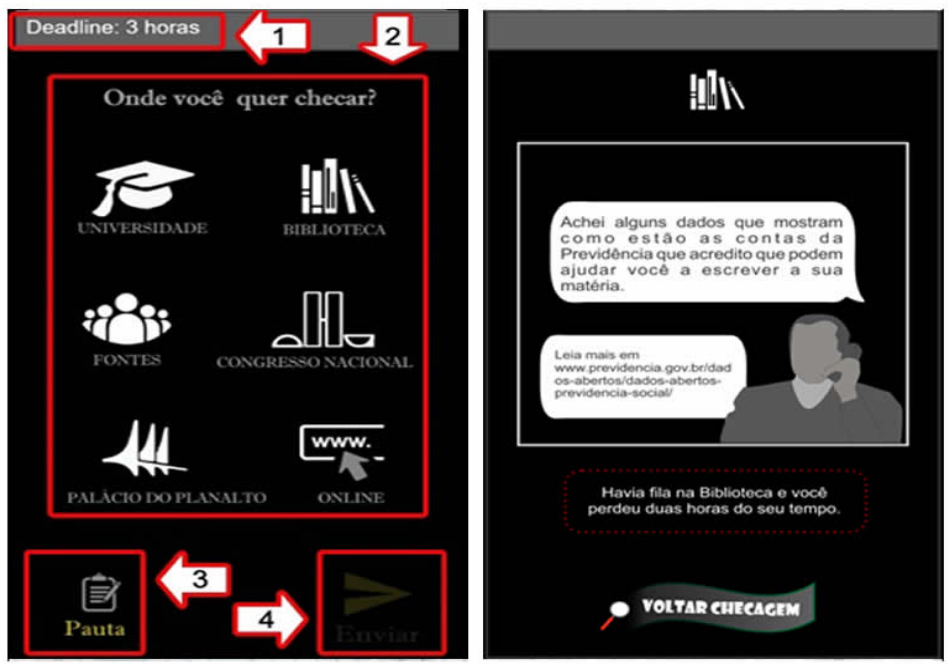

Fonte: https://marciano.itch.io/fact-checking 
Se o jogador perder o deadline ou considerar falsa uma informação verdadeira, e vice-versa, ele então atinge a condição de derrota. Caso ele faça a apuração correta, a condição de vitória é alcançada. Assim, o requisito "e" também foi contemplado.

Figura 14: newsgame - Fact-checking - Tela resposta errada (esq) e promoção (dir)
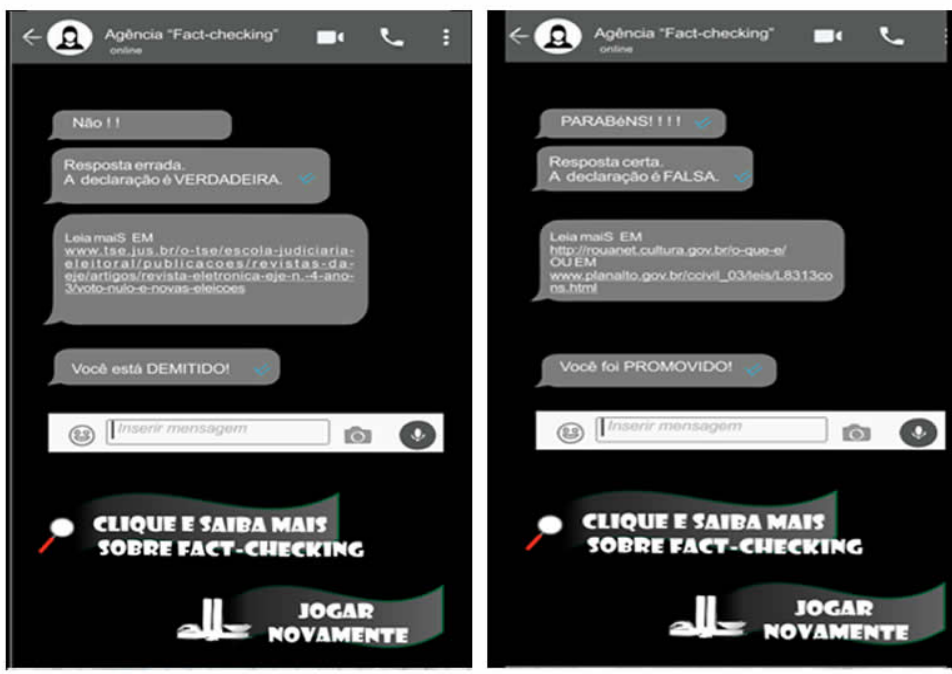

Fonte: https://marciano.itch.io/fact-checking

Já o requisito " $d$ " foi alcançado na medida em que o tema escolhido pela equipe está representado nos gráficos do newsgame, bem como nos textos das pautas e informações dadas pelas fontes.

\section{Mete a Colher ${ }^{4}$}

Desenvolvido pelos estudantes Ana Paula Bourscheid, Ânderson Silva, Frederico de Carvalho, Mariane Pires Ventura e Paulo José Mueller, este newsgame aborda como temática a violência contra a mulher.

Em um cenário que remete a orla de Florianópolis, o jogador controla um personagem que presencia situações de violência contra a mulher, sendo necessário decidir então se ele ignora e segue adiante ou "mete a colher", interferindo no caso.

Além de atender ao requisito "a", apresentando o título do jogo e o botão para jogá-lo, o menu também contempla o requisito "f", ao apresentar o botão "ler a matéria" que, se acionado, abre em uma nova aba do navegador a reportagem que sustenta $o$ newsgame. 
Figura 15: newsgame Mete a Colher - Tela de menu

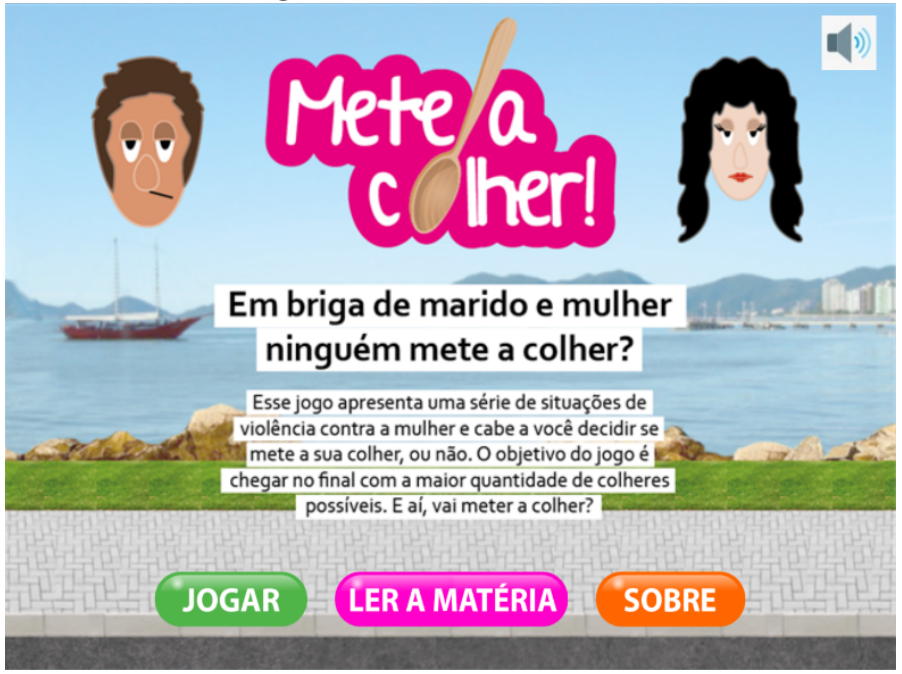

Fonte: https://marciano.itch.io/ng-meteacolher

Na tela de sobre é possível observar o cumprimento do requisito " $c$ ", pois o texto sinaliza o contexto em que o newsgame foi desenvolvido. Ainda nessa tela observa-se que o requisito " $b$ " foi cumprido parcialmente, na medida em que os nomes dos desenvolvedores estão descritos, mas não são especificadas suas funções.

Figura 16: newsgame Mete a Colher - Tela de sobre

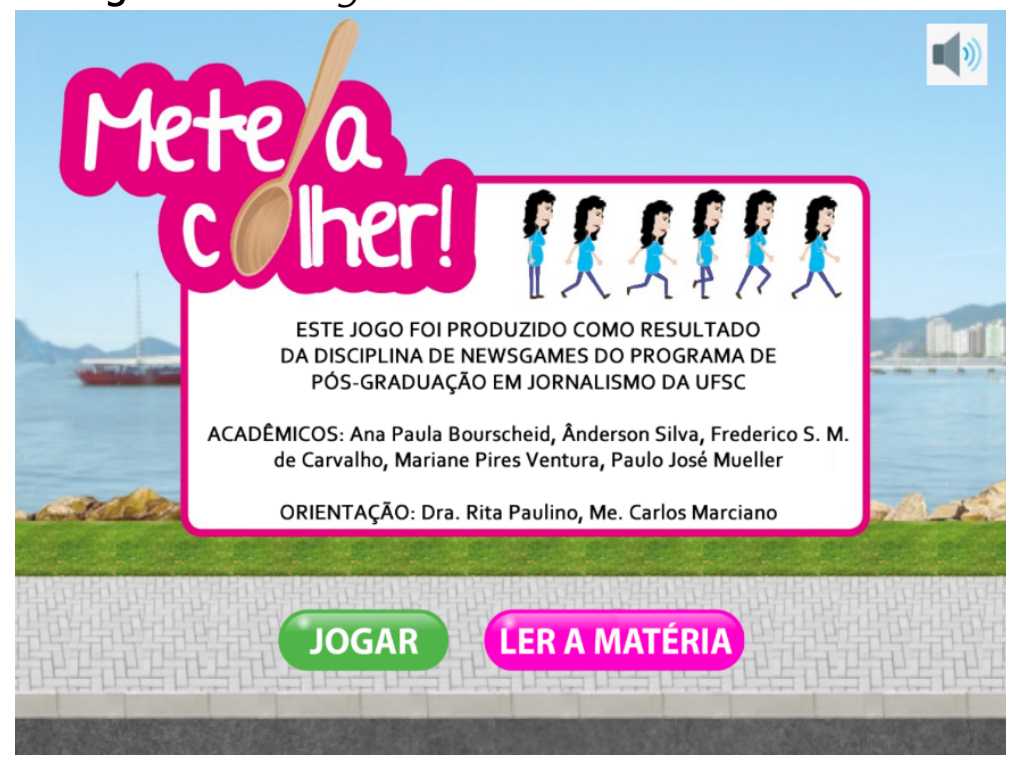

Fonte: https://marciano.itch.io/ng-meteacolher

Ao clicar em jogar é possível selecionar um personagem masculino ou feminino, mas ambos interagem da mesma maneira no gameplay. Em um estilo de jogo que mescla as mecânicas de plataforma e quizz, o jogador caminha pelo cenário até se deparar com uma situação em que alguma mulher está sofrendo violência. 


\section{Obevisto}

Nesse momento uma tela mostra a situação e pergunta se o jogador quer ignorar ou interferir. Escolhendo a primeira opção, ele continua o jogo normalmente, mas antes aparece um texto com estatísticas sobre a violência contra mulheres.

Figura 17: newsgame Mete a Colher - tela de escolha

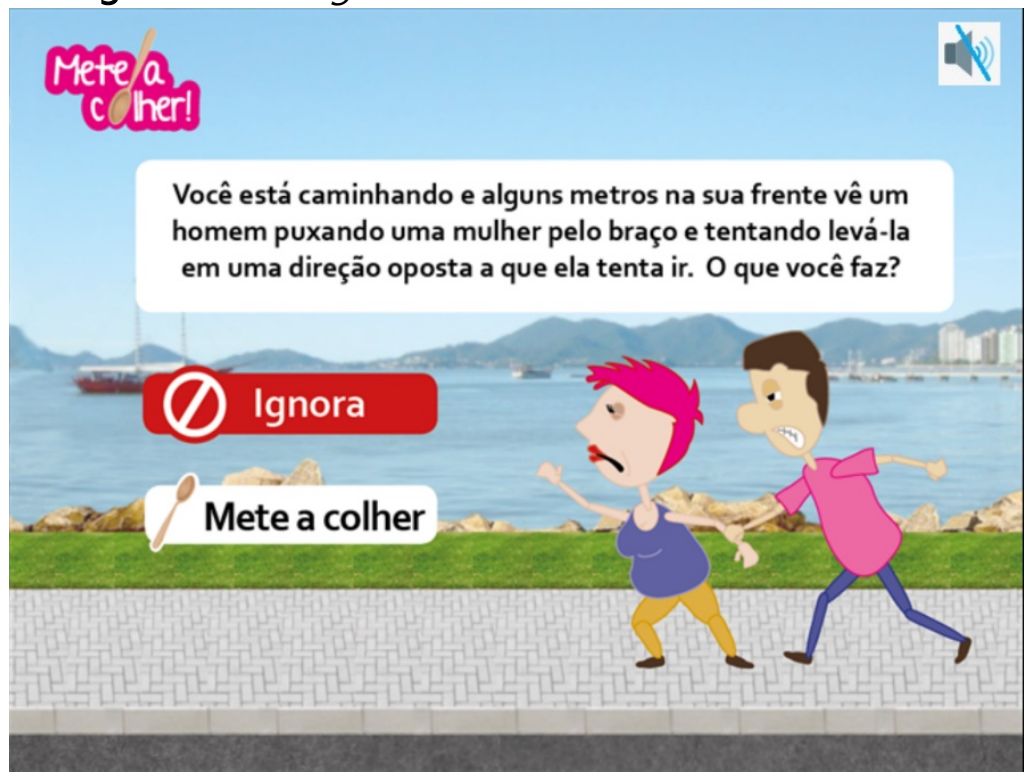

Fonte: https://marciano.itch.io/ng-meteacolher

Figura 18: newsgame Mete a Colher - estatísticas aparecem ao ignorar

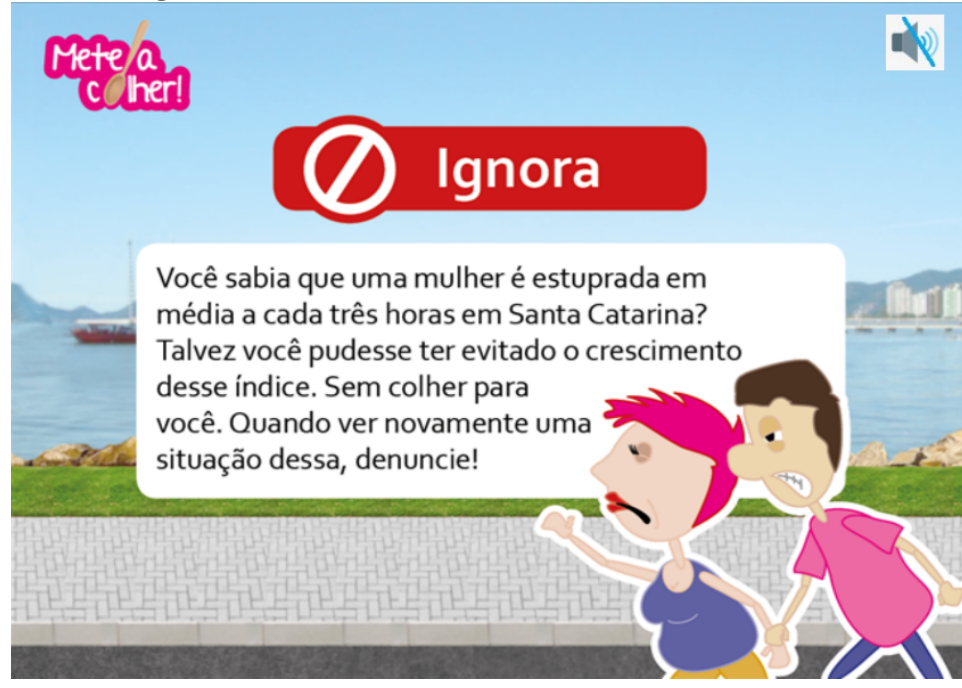

Fonte: https://marciano.itch.io/ng-meteacolher

No entanto, se o jogador optar por interferir, é apresentado a ele quatro ações possíveis. Caso escolha a opção errada a próxima tela irá indicar o erro e mostrar a alternativa correta. 
Figura 19: newsgame Mete a Colher - Tela de opções (esq) e alerta de erro (dir)

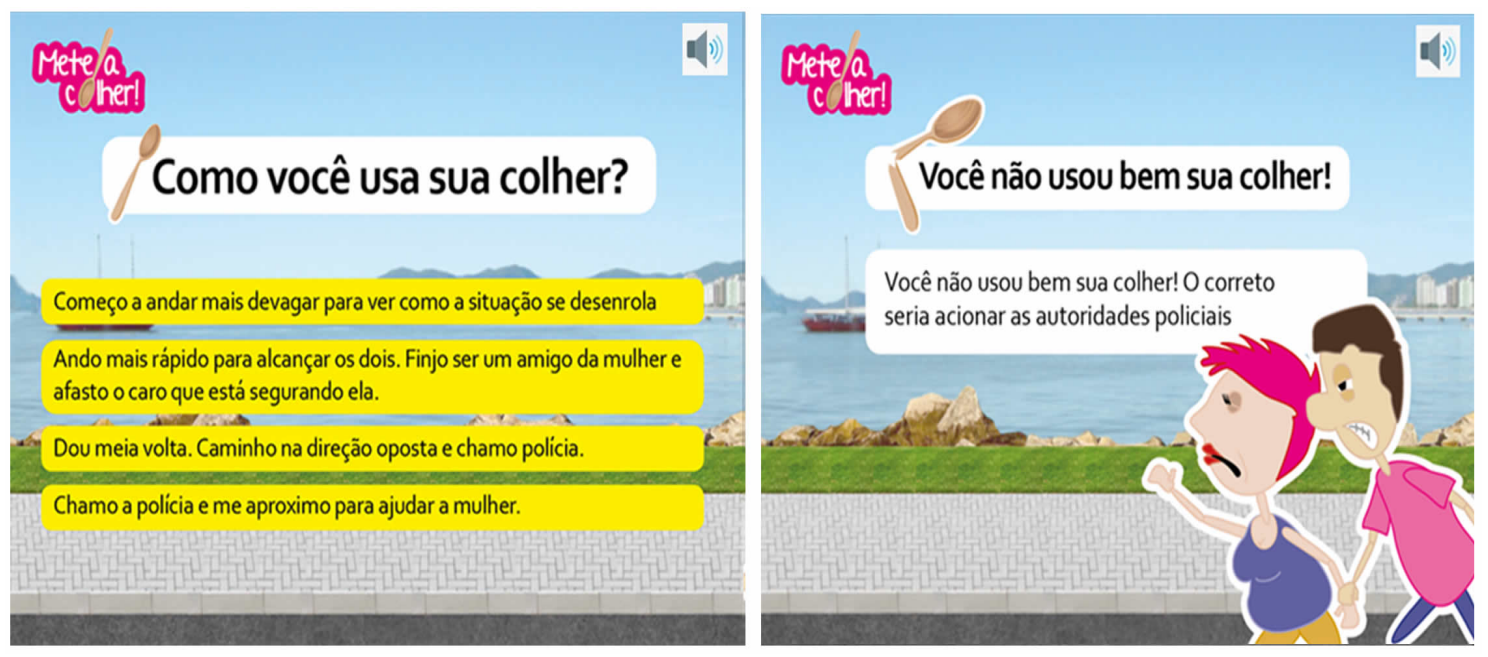

Fonte: https://marciano.itch.io/ng-meteacolher

Se ele acertar a questão, a tela seguinte indica o acerto e uma colher é realçada na parte superior da tela (1). São cinco colheres ao todo, de modo que ele já começa com uma, podendo ganhar as outras quatro, caso tenha êxito nas respostas.

Figura 20: newsgame Mete a Colher - Ao acertar o jogador ganha uma colher
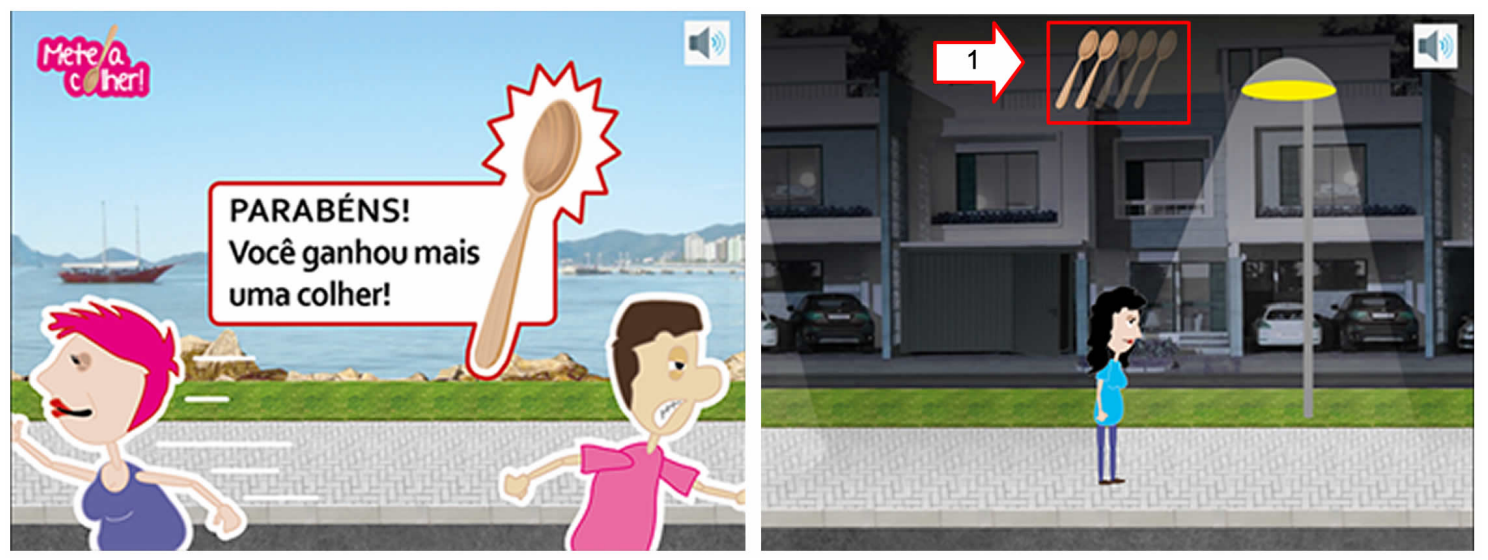

Fonte: https://marciano.itch.io/ng-meteacolher

Após presenciar as quatro situações o jogador é direcionado para a tela final do newsgame, independente se ele acertou, errou, ou ignorou os questionamentos. A quantidade de acertos é indicada pelo número de colheres realçadas na parte superior.

Pelo texto logo abaixo das colheres é possível verificar em qual das quatro categorias o jogador se enquadra, mediante o resultado obtido. 
Figura 21: newsgame Mete a Colher - Tela final.

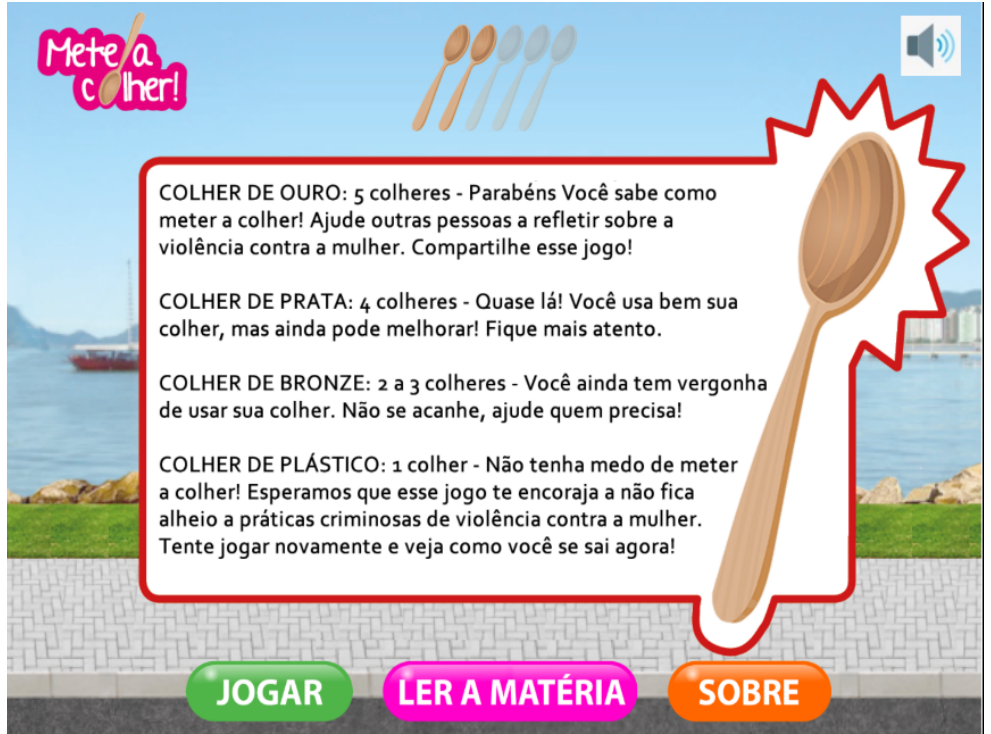

Fonte: https://marciano.itch.io/ng-meteacolher

O requisito " $\mathrm{d}$ " é alcançado no newsgame, pois o tema escolhido é representado nos textos e elementos gráficos. Embora o jogo não tenha telas de vitória ou derrota, pode-se afirmar que o requisito "e" também foi atingido, na medida em que cabe ao jogador analisar o seu resultado e constatar se ele ganhou ou perdeu o jogo.

Se compararmos dois jogadores, aquele que conseguiu mais colheres saiu vitorioso, no entanto nesse newsgame os desenvolvedores optaram por não colocar condições de vitória ou derrota justamente para que o jogador reflita sobre o seu desempenho.

Quem conseguiu poucas colheres pode rever suas ações para melhorar o resultado, já aquele que conseguiu coletar todas as cinco pode passar adiante o aprendizado sobre o tema.

\section{Considerações finais}

O avanço tecnológico permite que a informação jornalística chegue cada vez mais longe, no entanto, também traz novos desafios, como a luta para combater as fakes news e a busca por transmitir os conteúdos de forma cada vez mais dinâmica e atrativa.

Nesse cenário, é evidente que não cabe mais apenas transcrever os assuntos dos meios tradicionais para o digital, é preciso compreender esse ecossistema, desvendar novas ferramentas, integrar o jornalismo com outras áreas.

Utilizar os newsgames nesse contexto é promissor, mas é preciso ter em mente que "um newsgame que só diverte, que não apresenta informação ou propõe reflexão sobre o assunto abordado é apenas um jogo" (MARCIANO, 2020, p.39). 
Antes de sair colocando a mão nos códigos demasiadamente é preciso refletir sobre como fazê-lo, seguir uma lógica consistente para que o conteúdo jornalístico não seja sucumbido pela diversão.

Conforme relatado anteriormente, a oficina aqui apresentada tinha como objetivos:

a) apresentar o Game Design Document para Newsgames (GDDN) a fim de verificar se os tópicos expostos estavam claros a ponto de os participantes conseguirem planejar um jogo seguindo-os;

b) auxiliar as equipes quanto à programação no software Construct 2 para que conseguissem desenvolver ao menos uma das fases planejadas no GDDN.

A partir dos resultados foi possível constatar que ambos foram alcançados, visto que os alunos compreenderam as diferenças entre newsgames e Jogos Embasados em Notícias (JEN), desenvolveram o GDDN e conseguiram programar ao menos uma fase do newsgame proposto.

A pesquisa aplicada retratada nesse trabalho visa quebrar o estereótipo de que a ideia de inserir jogos no jornalismo é interessante, mas a prática parece distante e complexa: a teoria expressada e os jogos desenvolvidos a partir dela mostram que é possível produzir newsgames de qualidade, independente se você é um acadêmico ou profissional do mercado.

Vale destacar ainda que o desenvolvimento dos newsgames na oficina aconteceram em duas etapas:

1 - planejamento do jogo através do preenchimento dos tópicos do GDDN;

2 - desenvolvimento do jogo com a utilização do software Construct 2.

Caso o método da oficina seja replicado, recomenda-se que os envolvidos sigam esse passo e primeiro estruturem o jogo a partir do GDDN.

Desse modo, mesmo que no grupo de trabalho não exista algum integrante com conhecimento de softwares para desenvolvimento de jogos (como Construct, Unity, Unreal, etc), a base teórica do newsgame estará pronta e esse profissional habilitado poderá ser encontrado posteriormente. 
Afinal, caso não seja possível codificar o newsgame, sua sistematização através do GDDN também é válida.

Desenvolver newsgames não é tarefa fácil, requer disciplina, comprometimento e dedicação. A metodologia aqui apresentada visa justamente tornar esse caminho menos penoso, dando uma direção para aqueles que desejarem planejar, orientar e desenvolver os jogos jornalísticos

Assim, espera-se que tomando como guia a estrutura do Game Design Document para Newsgame (GDDN) e o método aqui exposto, empenhando-se no propósito de replicá-lo, o resultado seja o planejamento ou concepção de uma ferramenta jornalística inovadora e lúdica, levando a informação para além do entretenimento.

\section{Referências}

BOGOST, I.; FERRARI, S.; SCHWEIZER, B. (2010). Newsgames Journalism at Play. ed. Massachusetts: Massachusetts Institute of Technology.

FRASCA, G. (2003). Simulation versus Narrative: Introduction to Ludology. In: Wolf, Mark J. P; Perron, Bernard. The Video Game Theory Reader. New York: Routledge, pp. 221-235. Recuperado em 28 março, 2021, de: <https://goo.gl/NwXmsN>

LAGE, N.(2001). Ideologia e Técnica da Notícia. 3. ed. Florianópolis: Insular/UFSC.

MARCIANO, C. N. (2020). Da pauta ao play: proposta metodológica para o planejamento e desenvolvimento de newsgames. Tese (Doutorado em Jornalismo) Universidade Federal de Santa Catarina. Florianópolis, p.434.

MORAN, J.(2021). Metodologias ativas para uma aprendizagem mais profunda. 2013. Recuperado em 21 março, 2021, de: < https://goo.gl/Jn3duj>

ROGERS, S.(2014). Level up: the guide to great video game design. United Kingdom: John Wiley \& Sons.

SICART, M.(2008). newsgames. Theory and Design. International Conference on Entertainment Computing. Pittsburgh.

TREANOR, M., MATEAS, M. (2009). Newsgame. Procedural Rhetoric Meets Political Cartoons. Brunel University, London, 2009. Recuperado em 3 março, 2021, de: < https://www.researchgate.net/publication/255590174_Newsgames_Procedural_Rh etoric_meets_Political_Cartoons> 


\section{arevisto Observatório}

\begin{abstract}
:
Newsgames are gaining more and more space as a new language of journalism, bringing information through the playfulness of games. In this sense, stimulating the development of this tool becomes crucial. This article derives from a doctoral thesis that uses applied research to establish a methodology for the development of newsgames. Thus, the synthesis of the work is presented here, highlighting the key concept of the Game Design Document for Newsgames (GDDN), in addition to the method used in the workshop for the planning and development of journalistic games, held at the Federal University of Santa Catarina (UFSC), which brought together professionals from the labor market, undergraduate and graduate students.
\end{abstract}

KEYWORDS: newsgames, applied research, journalism

\begin{abstract}
RESUMEN:
Los juegos de noticias están ganando cada vez más espacio como un nuevo lenguaje del periodismo, trayendo información a través de la diversión de los juegos. En este sentido, estimular el desarrollo de esta herramienta se vuelve crucial. Este artículo deriva de una tesis doctoral que utiliza la investigación aplicada para establecer una metodología para el desarrollo de newsgames. Así, aquí se presenta una síntesis del trabajo, destacando el concepto clave del Game Design Document para Newsgames (GDDN), además del método utilizado en el taller de planificación y desarrollo de juegos periodísticos, realizado en la Universidad Federal de Santa Catarina (UFSC), que reunió a profesionales del mercado laboral, estudiantes de pregrado y posgrado.
\end{abstract}

PALABRAS-CLAVES:

investigación aplicada, periodismo 